\title{
FURTHER DEVELOPMENT OF THE EBBSFLEET WATER MANAGEMENT SYSTEM DYNAMICS MODEL: ADJUSTING REPRESENTATION OF PROCESSES AND SYSTEM BOUNDARIES, INCENTIVISING STAKEHOLDER RE-ENGAGEMENT, AND EXPLORING POTENTIAL FOR UNIVERSITY TEACHING
}

\author{
VLADIMIR KRIVTSOV ${ }^{1,2,3}$, ALESSANDRO PAGANO ${ }^{4}$, SANGARALINGAM AHILAN ${ }^{5}$, \\ EMILY O'DONNELL ${ }^{1} \&$ IRENE PLUCHINOTTA ${ }^{6}$ \\ ${ }^{1}$ University of Nottingham, UK \\ ${ }^{2}$ RBGE, UK \\ ${ }^{3}$ University of Edinburgh, UK \\ ${ }^{4}$ Water Research Institute, National Research Council, Italy \\ ${ }^{5}$ University of Exeter, UK \\ ${ }^{6}$ University College London, UK
}

\begin{abstract}
Sustainable urban water management must address interconnected social, technical and environmental issues. Modelling helps us understand these interconnections and provides a tool to analyse interactions between the urban water system and alternative management strategies. Models may be used to simulate not only the effects of climate, social and economic changes, but also the impacts of technological innovations, and different policy interventions. This paper reports an update of the Ebbsfleet Water Management System Dynamics Model (SDM) that explores sustainable urban water management. The model is open-source compiled using Vensim software, which is free for non-commercial use. This paper demonstrates that the current SDM and the modelling approach are open to adjustment, which is illustrated by introducing a link between water tariffs and environmental awareness. The increase in water tariffs leads not only to the obvious increase in water bills, but also to an increase in Environmental Awareness, and consequently, to increases in the use of water efficiency devices, grey water acceptability, and grey water reuse. A range of further modifications is suggested, including expanding representation of sustainable drainage systems (SuDS) to consider resultant improvements in stormwater quality as well as quantity. This would recognise the indirect benefits of improved stormwater quality on biodiversity in the River Ebbsfleet, which is the receiving watercourse. This study intends to encourage knowledge transfer, by facilitating and incentivising the use and further development of the SDM by stakeholders and a wider community of end-users, including practitioners, academics and the public. While SDM is particularly suited to analysis of indirect relations, benefits and trade-offs among system constituents, other approaches provide viable alternatives and we discuss the potential for re-implementing our findings in other interactive modelling software packages and programming languages. We also explore the scope for linking the adapted SDM to other models. Finally, we consider the utility of the Ebbsfleet SDM in teaching, learning and knowledge transfer. We conclude that students, practitioners and other stakeholders could not only enhance their understanding of urban water management complexity, but also gain valuable system modelling skills based on using the SDM to support kinaesthetic learning. Ultimately, society benefits when the level of knowledge and analytical thinking skills of its members are enhanced.
\end{abstract}

Keywords: water balance, system thinking, water security, societal benefits, sensitivity analysis, nature-based solutions, industrial ecology, public engagement, pricing policy, 'what-if' scenarios.

\section{INTRODUCTION}

Urban water and flood risk management are increasingly regarded as essential components in sustainable and healthy living as well as economic activities in cities [1]-[3]. Modern 
urban water management is a very complex process associated with a multitude of interconnected social, technical and environmental issues [4]. A growing number of issues is expected to emerge concerning sustainable water resources management. Simulation modelling has been historically used for increasing the understanding of dynamically evolving urban water systems as it helps to elucidate this complexity and provides a potential tool for the analysis of interactions between system components. It also enables the assessment of a wide range of urban water management strategies related to technological innovations, policy interventions, climate change and meteorological variability, and social and economic issues [5], [6].

Three types of simulation modelling approaches are commonly used to explore urban water management and governance: urban water metabolism [7], [8], agent-based [9] and system dynamics modelling [10]-[12]. The metabolism-based modelling approach overcomes issues commonly encountered by independent modelling of the components of the urban water system (water supply, wastewater and surface water collection) by providing an integrated approach that considers the interconnection and interdependencies between water flows and other fluxes in urban systems including wastewater, energy and material. This integrated modelling approach enables the urban water system to be modelled over longterm planning horizons for both business as usual and future intervention strategies such as rainwater harvesting, greywater recycling, and wastewater reuse. While urban water metabolism provides a holistic picture of urban water management, there are several challenges and limitations in developing a detailed metabolic model e.g. data availability and uncertainty at high resolution [13]. Agent-Based Modelling has been used as well, but also with limitations e.g. in providing a comprehensive and cross-sectoral analysis of complex urban systems and in the analysis of future evolution through 'what-if' scenarios [9]. The System Dynamics Modelling approach is able to incorporate both the dynamic evolution of the urban system as well as social conditions such as stakeholders' priorities and goals. The multiple strengths of this approach have led to the development of many user-friendly interactive modelling tools such as STELLA, ModelMaker, Madonna, Simile and Vensim.

System dynamics modelling that investigates and subsequently resolves complex issues related to urban ecology and water management may be particularly fruitful when carried out together with stakeholders. The participatory process involving collaboration between a diverse community of practitioners and university researchers within the Ebbsfleet 'Learning and Action Alliance' (LAA) has been documented previously in comprehensive detail [14]. This paper aims to report on recent (i.e. after the publication of the initial paper) developments and further plans related to the Ebbsfleet System Dynamics Model (SDM). It therefore adds value in relation to the previous work, and has the following objectives:

- to demonstrate that the current SDM and the modelling approach are open to adjustment by modifying the model and suggesting further modifications;

- to demonstrate the capacity of the model to analyse indirect interrelations among system components;

- to identify the scope of linking the Ebbsfleet SDM to other models;

- to encourage knowledge transfer, by facilitating and incentivising the use and further developments of the SDM by stakeholders and a wider community of end-users, including practitioners, academics and the public;

- to identify and explore possibilities of using the Ebbsfleet SDM as a case study for teaching of simulation modelling, system dynamics, water security, and water management. 


\section{EBBSFLEET GARDEN CITY AND THE NEED FOR SDM}

Ebbsfleet Garden City is situated on the bank of the River Thames and is part of the national government initiative to create a new Garden City in north Kent in response to the growing housing demand in South East England. The city aims to provide up to 15,000 good quality new homes built over twenty years (2015-2035), predominantly on former quarries, brownfield land and previously developed industrial sites. The development straddles the boundaries of Gravesham and Dartford districts and includes a number of strategic sites. The Ebbsfleet Development Corporation is a government organisation that actively works with landowners, developers, and water companies to successfully implement the development framework. In the Garden City, the water supply comes from both Thames $(67 \%)$ and Southern Water (33\%) and the wastewater management is largely dealt with by Southern Water. A growing population, water scarcity, prevailing complex landscape features, ageing infrastructure and involvement of multi-stakeholders in decision making highlight a need for a joined-up planning approach for sustainable integrated urban water management in Ebbsfleet. To meet this need, the system dynamics modelling approach has been used within the Urban Flood Resilience (UFR) project to explore sustainable water management in the Garden City [14]. As part of the participatory modelling process, a LAA was established, involving a range of key stakeholders (Thames Water, Southern Water, Ebbsfleet Development Corporation, Kent County Council, Dartford and Gravesham Borough Councils, among others). It should be noted that both the Ebbsfleet LAA and the SDM have been documented in comprehensive detail previously [14], and only a brief overview of the original model will be given in this paper. Further details, in particular the list of the equations, can be found in the previous publication whilst both the code and the compiled model are available from the authors.

\section{EBBSFLEET SDM}

The previously developed stock and flow model focused on one of the problem dimensions (sustainable urban water supply management) that emerged during the participatory exercises that were carried out in the Ebbsfleet Garden City. Based on a comprehensive conceptual system analysis (allowed also by the development of a set of Causal Loop Diagrams (CLD) in early stages of stakeholders' involvement) and complemented by relevant technical/scientific information (both provided by experts in Urban Water Management and available in the scientific literature), the model aims to explore, in a structured way, the evolution of the system over a 30 year time span and the potential effectiveness of multiple policy interventions. Indeed, one of the main advantages of using an SDM is the quantitative analysis of the impacts of manifold strategies that can be performed on the technical side (e.g. increase of the supply), on the socio-cultural side (e.g. educational programmes for water saving) or on the economic side (e.g. introduction of a water tariff). The model can be used to compare the effectiveness of different strategies as well as analysing their potential synergistic effects, mutual influences, unintended consequences and trade-offs.

The model (Fig. 1) computes a basic hydraulic water balance at the urban level (i.e. a comparison between water demand and water supply), performed at a yearly time step, and considers aggregated behaviour over the whole urban area (i.e. no individual or microbehaviours are modelled). Specific attention, based on inputs provided by the stakeholders, is given to the analysis of the role of sustainable water saving/management strategies such as Rainwater Harvesting (RWH) and Grey Water Reuse (GWR). The model comprises stocks (i.e. accumulations related to real-world categories such as materials or knowledge, drawn with rectangles), flows (rates of change in the value of stocks, drawn with an arrow with a valve), variables (dynamic variables, used to define intermediate concepts and changing 
instantaneously according to an equation, and numeric constants) and links (arrows denoting a dependency between elements of a stock and flow diagram).

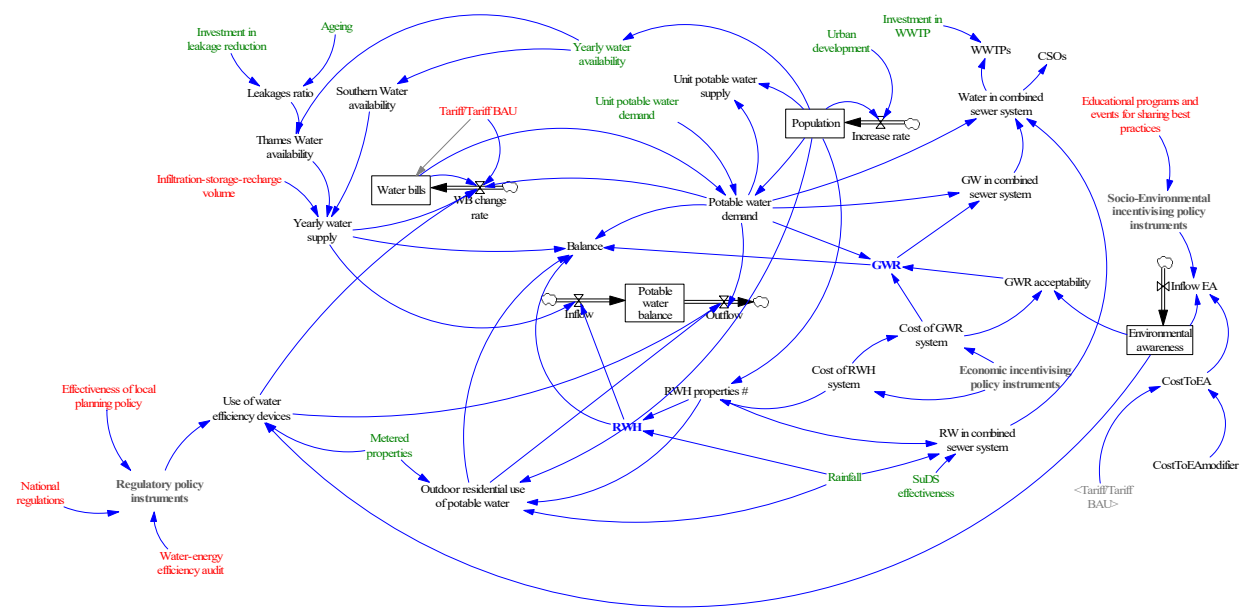

Figure 1: Diagram of the Ebbsfleet SDM with an example of structural modification introducing a link between water tariffs and environmental awareness. Note that different colours are just a historic legacy (they simply refer to the stages at which the components were added during the model development).

It should be noted that the different colours in Fig. 1 are a historic legacy and refer to the stages at which the components were added during the model development. For example, the variables in green identify the first set of input variables selected with the stakeholders. The variables in red identify additional input variables added during the last workshop which aim to represent measures/policies capable of modifying the state of the system and its dynamic evolution. These colours are not essential for further development and users are encouraged to modify the colour scheme to represent their own preferences.

The representation of processes necessary to calculate the water balance in the Garden City have been detailed in the previous publication [14]. A brief overview is given below. The water supply depends on the 'availability' of water from both Thames Water Utilities Limited (for which the influence of 'leakages ratio' is explicitly considered) and Southern Water. The 'Infiltration-storage-recharge volume' is an additional volume that could theoretically be considered if specific actions are implemented. The global 'yearly water availability' is assumed to match the current per capita water consumption. The demand directly depends on the dynamics of the 'population' stock which follows the 'urban development' plan. A total of 12,000 houses (with average occupancy of three people) is foreseen by the end of the project. An interconnection between water supply and demand is explicitly considered, regulated by the 'water bill'. A baseline unit value (corresponding to the current water tariff) is considered, but an increase can be either activated under specific conditions (please refer to the model equations for full details) or limited by the "use of water efficiency devices'. In the present work, a connection between the water bill and the 'environmental awareness' is also explored, as detailed in the next section. This connection reflects both the observational evidence and suggestions voiced by a minority of stakeholders during the LAA workshops. 
In addition to the processes noted above, the water balance is affected by specific water saving measures (RWH and GWR), whose role is explicitly described in the model. The contribution of RWH systems is related to both the fraction of households with such systems installed out of the total number of properties ('RWH properties') and to the 'Rainfall', and contributes to the reduction of the 'outdoor residential use of potable water'. The uptake of RWH is considered to be directly dependent on the economic feasibility ("cost of RWH system'). The role of GWR is directly dependent on both the level of 'GWR acceptability' by the end-users (which is affected by the 'environmental awareness'), and on the 'Cost of GWR systems'. Both RWH and GWR, besides reducing the potable water demand, contribute to reduce the volumes of 'water in combined sewer systems'.

One of the key elements of the model is represented by the 'environmental awareness', which affects the 'GWR acceptability' as well as the 'use of water efficiency devices'. A direct influence of 'Socio-Environmental incentivising policy instruments' on the 'environmental awareness' is considered, as well as, for the purposes of the present work, on the water pricing policy. Several 'regulatory policy instruments' influence the 'use of water efficiency devices'.

The main output of the model is the 'Potable water balance', which is directly or indirectly affected by all the processes and model components mentioned above. It is worth highlighting that negative values of the potable water balance identify a potential water supply deficit. Conversely, positive values are mainly related to the assumption that the 'supply side' does not adapt with time e.g. to the reduction of potable water demand that would be associated to GWR and RWH or any other corrective action. In other words, the water supply follows an increasing water demand calculated according to the increase in population and a reference per capita water consumption. It should be noted that 'Potable water balance' is modelled as a stock. Its dynamics, therefore, result from differences between 'inflow' and 'outflow' and is described using a differential equation. For convenience, there is also a variable called 'Balance', which tracks the annual differences between the sum of replenishing processes (yearly water supply, RWH and GWR) and the sum of demands (i.e. potable water demand and the outdoor residential use of potable water).

\section{LIMITATIONS OF THE PUBLISHED MODEL AND POTENTIAL FOR FURTHER DEVELOPMENTS}

It is of course worth reiterating that any model is inevitably a simplification of reality, and any modelling effort is limited by time, logistical and financial constraints. Furthermore, the published SDM model [14] was designed in accordance with the outcome of discussions held during the LAA workshops, and is therefore constrained by the system boundaries and structural relationships thus imposed. It should, however, be noted that the current model structure is open to adjustment, and the users are indeed encouraged to explore not only developing further scenarios, but also making modifications to the model structure. Vensim software, which is sufficiently user-friendly and free for non-commercial use, was specifically chosen to enable further developments of the model by the end users.

\subsection{Modification 1: Linking water tariffs and environmental awareness}

One possible simple modification of the current model structure could be a link between water tariffs and environmental awareness (Fig. 1). The modified model diagram contains an explicit representation of the 'Tariff/Tariff BAU' parameter, i.e. the ratio between the water tariff used in any particular simulation and the baseline water tariff (BAU refers to Business As Usual). Although this parameter has previously been included in model definitions (see 
equation 38 in the original model), it was for simplicity omitted from the original model diagram as increase in tariffs was not investigated [14]. It should also be noted that 'Tariff/Tariff BAU' on the current diagram appears in two places; in addition to its original placement next to 'Water Bills' it is also shown on the right side of the diagram as a shadow variable.

The modified CLD also contains two completely new definitions: a parameter CostToEAmodifier and a variable CostToEA. The latter is described by the following equation:

$$
\text { CostToEA }=1+\left({ }^{\prime} \text { Tariff } / \text { Tariff } B A U^{\prime}-1\right) * \text { CostToEAmodifier }
$$

The equation 'Inflow EA' has also been changed to include multiplication by CostToEA. Depending on the value of the CostToEAmodifier parameter, the increase in water tariff will be transferred to the 'Inflow EA' using CostToEA variable either with no change (if CostToEAmodifier $=1$ ), with reduction (if $0 \leq$ CostToEAmodifier $<1$ ), or with amplification (if CostToEAmodifier $>1$ ). When CostToEAmodifier $=0$, the increase in tariff will not be transferred and the modified model becomes equivalent to the original model.

Fig. 2 presents the simulation results for scenarios detailed in Table 1. Scenarios T25up and T50up explore the influence of, respectively, $25 \%$ and $50 \%$ increase in water tariffs,

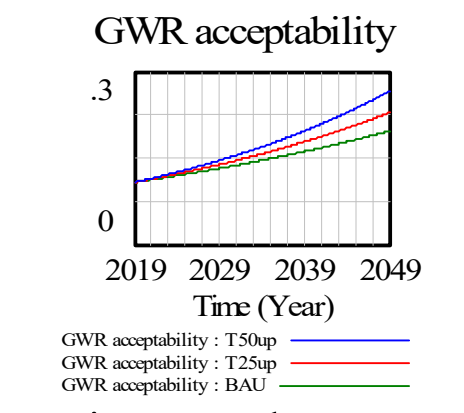

Environmental awareness

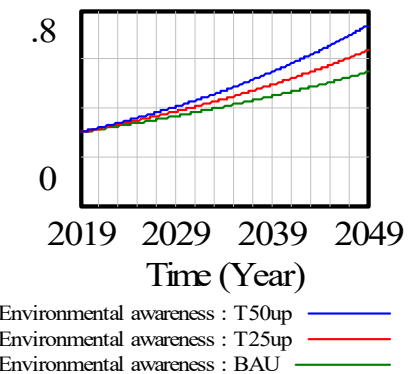

GWR

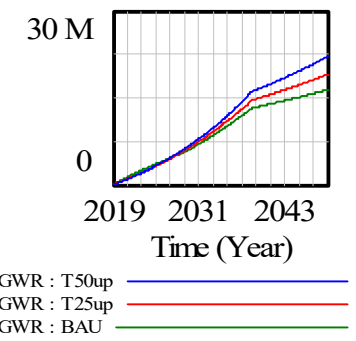

Environmental awareness

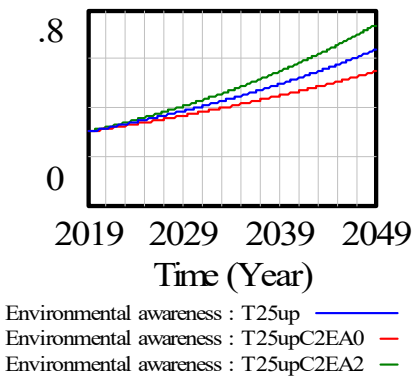

Figure 2: Examples of the simulation runs obtained using the modified model. The upper panels and lower left panel show the results of sensitivity analysis for the 'Grey Water Reuse' (GWR), 'Environmental Awareness' and 'GWR acceptability' variables on changes in the 'Tarif/Tarif BAU' parameter. The lower right panel presents the results of sensitivity analysis for 'Environmental Awareness' variable on the CostToEAmodifier parameter. The parameter values for these runs are given in Table 1. 
Table 1: Parameter values used for specific scenarios.

\begin{tabular}{|l|l|l|l|}
\hline Scenarios & $\begin{array}{l}\text { CostToEA } \\
\text { modifier }\end{array}$ & $\begin{array}{l}\text { 'Tariff/Tariff } \\
\text { BAU' }\end{array}$ & Comments \\
\hline BAU & 1 & 1 & $\begin{array}{l}\text { This is the baseline scenario, but with an } \\
\text { introduced link between the tariffs and } \\
\text { 'Environmental Awareness' }\end{array}$ \\
\hline T25up & 1 & 1.25 & $\begin{array}{l}\text { This scenario simulates a 25\% increase } \\
\text { in water tariffs }\end{array}$ \\
\hline T50up & 1 & 1.5 & $\begin{array}{l}\text { This scenario simulates a 50\% increase } \\
\text { in water tariffs }\end{array}$ \\
\hline T25upC2EA0 & 0 & 1.25 & $\begin{array}{l}\text { This scenario simulates a 25\% increase } \\
\text { in water tariffs but disables the link } \\
\text { between the tariffs and 'Environmental } \\
\text { Awareness' }\end{array}$ \\
\hline BAU0 & 2 & 1.25 & $\begin{array}{l}\text { This scenario simulates a 25\% increase } \\
\text { in water tariffs and augments its } \\
\text { influence on 'Environmental Awareness' }\end{array}$ \\
\hline & 0 & 1 & $\begin{array}{l}\text { With this combination the model } \\
\text { simulations become equivalent to the } \\
\text { baseline simulations of the original } \\
\text { model }\end{array}$ \\
\hline
\end{tabular}

whilst scenarios T25upC2EA 0 and T25upC2EA2 combine the $25 \%$ increase in water tariffs with changes in the value of the CostToEAmodifier parameter. The increase in water tariffs leads not only to the obvious increase in water bills (not shown), but also to the increase in Environmental Awareness, and consequently to the increases in the use of water efficiency devices, Grey Water acceptability, and Grey Water Reuse. However, there are no obvious changes in the dynamics of any other variables examined (data not shown).

It is also evident that changes in the value of the CostToEAmodifier parameter can be used to influence the link between Environmental Awareness and the water tariffs. For example, setting this parameter to 2 leads to the augmented increase in Environmental awareness, and consequently to the enhanced increases in the use of water efficiency devices (not shown), Grey Water acceptability, and GWR. However, setting the value of the CostToEAmodifier parameter to 0 disables the structural link between Environmental Awareness and the water tariffs, and the modified model becomes equivalent to the original model.

Interestingly, the influence of water tariffs on water bills is not simple, but in fact consists of the combination of direct and indirect effects. The former is straightforward (users pay more when on a more expensive tariff), whilst the latter relates to behavioural changes that lead to a decrease in potable water consumption due to an increase in environmental awareness and the usage of water efficiency devices.

\subsection{Further modifications}

Further possible changes to the model may relate both to the interconnections of the variables already in the model, and to the changes in system boundaries. It is hoped that advanced users would help to develop new versions of the model, and whilst doing so would benefit from achieving a better insight into the complexity of interlinked processes related to the 
sustainable management of urban water supply. Below are just a few suggestions of such potential modifications.

\subsubsection{Modification 2}

In the original SDM, grey water is assumed to be discarded through a combined sewer system. It would, however, be very easy to include a detailed representation of the stormwater pathways, and also include SuDS components, e.g. swales, green roofs and retention ponds.

\subsubsection{Modification 3}

Following the implementation of Modification 2, it would be possible to consider the runoff water quality and assess the combined effects of hydrology and water chemistry on the biological community of the SuDS retention ponds, as well as impact on downstream ecosystems. Such a representation of SuDS for stormwater treatment and consideration of runoff chemistry [15] are particularly interesting for the analysis of indirect effects [16], [17] related to the water quality and biodiversity of the receiving water courses [18]-[21].

\subsubsection{Modification 4}

An interesting possible development of the model may be a simulation of retrofitting green roofs. Such a scenario would have implications both for the quality of harvested rainwater, and for the quality and quantity of runoff. The combination of these changes is likely to lead to some complex interactions comprised of both direct and indirect effects, and simulation modelling is a very useful tool for untangling those and clarifying the emerging patterns.

\subsubsection{Other modifications}

The implementation of modifications 3 and 4 presents a further possibility to assess the impact on local wildlife, and to compare the contributions of various scenarios towards local biodiversity enhancement. Further useful modifications may include a more comprehensive representation of the population changes in Ebbsfleet (i.e. considering changeable rates of birth, death and migration), linkages between water supply and demand, and the incorporation of the rebound effect. The rebound effect (also known as the 'efficiency paradox') refers to a potential increase in water consumption due to water price reduction, which may occur when more water becomes available in the system (e.g. due to the increase in the system's efficiency). This is only partially considered in the model in its current form, since the reduction of water bills causes an increase of potable water use, but could be easily explored further in the future.

\section{DISCUSSION AND CONCLUDING REMARKS}

Simulation modelling is helpful for understanding the patterns of interactions between and within complex social and environmental systems. System dynamics modelling is particularly useful as it provides a convenient tool for the analysis of interactions between system components and the assessment of a wide range of potential scenarios related to technological innovations, policy interventions, climate change and meteorological variability, and social and economic issues. This paper addresses further development of the previously published Ebbsfleet Water Management SDM, co-produced with the Ebbsfleet LAA. This is a new development, built on previous work where the structure of the SDM was largely determined by the stakeholders. While the participatory process facilitated by the LAA was very valuable, the stakeholders do not appear to use the final product (aside from potentially reading the published paper), hence there is scope for further enhancement and increase in impact. 
This paper demonstrates that the current SDM and the modelling approach used are open to adjustment, which is illustrated by introducing the link between water tariffs and the level of environmental awareness. The introduced changes are not only helpful in providing a more realistic representation of the selected processes, but also, importantly, aim to highlight to the potential end-user that the SDM is open to adjustment, and incentivise usage by stakeholders and further developments both by the stakeholders and the wider modelling community. Further suggestions regarding other potential modifications provide a number of starting points for future research.

\subsection{Plans for increasing impact through training events and incorporation in} teaching modules

It is worth reiterating that any model is a simplification of reality, and simulation models are limited by their scope (e.g. the imposed system boundaries) and the available research effort. The main value of the system dynamics participatory modelling process, however, is that all the parties involved enhance their understanding of the processes and interactions within the system considered. It is, therefore, stipulated that any modelling product is not rigidly dogmatic but rather open to adjustment, and that the stakeholders are not baffled by the apparent complexity but incentivised to use the product and to develop it further.

The example of simple structural changes to the Ebbsfleet SDM described in this paper provides an optional modification of the previously published model and aims to show to the potential end-user that both the processes represented in the model and their interlinkages can be easily adjusted. The users have full control over the product and can therefore make any modifications they like, including e.g. additions of new components and/or links between the already existing components. The system boundaries could be easily broadened, and the potential new developments may, for example, include representation of indirect impacts on biodiversity, water and air quality, local economy and human health. The output from the Ebbsfleet SDM may also be used as an input to other models.

To facilitate the use of the Ebbsfleet SDM by stakeholders, a series of online training events is currently being considered. These workshops aim to introduce the new users to the basics of simulation modelling and system dynamics, to help with installation and learning the Vensim software interface, to help troubleshoot any teething problems and provide the initial support in running the existing model, and to demonstrate the potential for structural modifications by guiding the users through some examples. The users would then be encouraged to implement further changes, and it is intended to provide feedback and support for their initial attempts. In addition, we are also currently exploring opportunities for using the Ebbsfleet SDM in university teaching. It is planned to compile a distribution bundle containing tutorials for Vensim software and the teaching materials related to the Ebbsfleet SDM. It is deemed that such training materials centred on an interdisciplinary modelling case study should be of use for undergraduate and master level modules related to a wide range of fundamental and applied disciplines, including e.g. Ecology, Geography, Engineering, Social and Environmental Sciences. Furthermore, discussions are currently underway as regards the development of the Environmental Modelling modules for the RBGE MSc course (Edinburgh, Scotland) and the ecology degree in Karazin University (Kharkov, Ukraine). It is intended that an introduction to the Vensim software and the Ebbsfleet SDM should constitute a major part of these modules, alongside other case studies relevant to water management, water quality and aquatic ecology, including the Lake 2 model J. Solomonsen [22] and the model Rostherne [23]-[25]. 


\subsection{Potential for using alternative software and links with other models}

The original model is open-source, compiled in the Vensim software, which is free for noncommercial use. It should be noted, however, that although the current version of the model is compiled in Vensim, there is no reason why interested users could not re-implement the model in other interactive modelling software such as Stella, Madonna or Simile. It would also be fairly straightforward to compile the Ebbsfleet SDM in most programming languages (e.g. Fortran, Visual Basic, C, Matlab) given that the model is open-source and all the equations have been documented previously in rather comprehensive detail [14]. In our opinion, Simulink and Matlab might be particularly convenient for the re-implementation and further development of the Ebbsfleet SDM (however, NB the costs). It should also be noted that the current definitions of the model contain only four differential equations (the rest are algebraic). By approximating those ordinary differential equations by difference equations, the model could be sufficiently simplified for an easy implementation in a spreadsheet, such as e.g. 'Calc' (for Linux), 'Numbers' (for Mac) or 'Microsoft Excel' (for Windows). The latter software in addition to the spreadsheet capabilities also has a built-in version of BASIC (i.e. VBA), and may, therefore, be particularly useful for debugging the spreadsheet model and comparing its output with the version based on differential equations.

The re-implementation and further development of the Ebbsfleet model in a programming language would help to overcome some of the major limitations of SDM. The model could be linked to a GIS, thus overcoming the inability to represent spatial processes. Also, the flexibility of most programming languages would allow easy access to a plethora of scripts shared by their user community. This, as well as an opportunity for writing new functions and sub-programs, would also create opportunities for representation of finer scale dynamics thus allowing another major constraint of SDM to be overcome and creating a more flexible, custom-built output. In particular, we envisage the scope of linking the adapted SDM to Urban Water Metabolism models. Such coupling would be very beneficial and would help to overcome the usual limitations in developing a detailed metabolic model e.g. data availability and uncertainty at high resolution. Furthermore, the system dynamics modelling approach may be particularly valuable for the analysis of indirect interrelations among system constituents thus enhancing flexibility of the water metabolism models.

\subsection{Overall relevance}

The optimisation of urban water management is key to the sustainable development of modern cities [4], [14]. System dynamics studies are very useful in that respect and have a potential added value of engaging practitioners and the public in further developments of the resulting models. Consequently, all users enhance their understanding of the underlying complexity through 'learning by doing' [26] and 'learning by example' [27], and ultimately, society benefits from the increased knowledge of its members. The research presented here has practical implications in helping to achieve and promote these intangible societal values, and is therefore contributing to the ongoing development of the Blue-Green Cities conceptual framework [1]-[3], [28], [29].

\section{ACKNOWLEDGEMENTS}

This research was part of an interdisciplinary project undertaken by the UFR Research Consortium (www.urbanfloodresilience.ac.uk). This work was supported by the UK Engineering and Physical Sciences Research Council (grant numbers EP/P004180/1, EP/P003982/1, EP/P004318/1). Colin Thorne is thanked for valuable discussion and edits. 


\section{REFERENCES}

[1] O'Donnell, E. et al., The blue-green path to urban flood resilience. Blue-Green Systems, 2(1), pp. 28-45, 2020.

[2] Fenner, R. et al., Achieving urban flood resilience in an uncertain future. Water, 11(5), 2019.

[3] D'Arcy, B. J., Kim, L.-H. \& Maniquiz-Redillas, M., Wealth Creation Without Pollution. Designing for Industry, Ecobusiness Parks and Industrial Estates, London: IWAP, 2018.

[4] Pagano, A., Pluchinotta, I., Giordano, R. \& Fratino, U., Integrating "hard" and "soft" infrastructural resilience assessment for water distribution systems. Complexity, 16, 2018.

[5] Pagano, A., Pluchinotta, I., Pengal, P., Cokan, B. \& Giordano, R., Engaging stakeholders in the assessment of NBS effectiveness in flood risk reduction: A participatory System Dynamics Model for benefits and co-benefits evaluation. Science of the Total Environment, 690, pp. 543-555, 2019.

[6] Pluchinotta, I., Pagano, A., Giordano, R. \& Tsoukiàs, A., A system dynamics model for supporting decision-makers in irrigation water management. Journal of Environmental Management, 223, pp. 815-824, 2018.

[7] Behzadian, K. \& Kapelan, Z., Modelling metabolism based performance of an urban water system using WaterMet2. Resources, Conservation and Recycling, 99, pp. 8499, 2015.

[8] Venkatesh, G., Brattebø, H., Sægrov, S., Behzadian, K. \& Kapelan Z., Metabolismmodelling approaches to long-term sustainability assessment of urban water services. Urban Water Journal, 14(1), pp. 11-22, 2017.

[9] Zhuge, C., Yu, M., Wang, C., Cui, Y. \& Liu, Y., An agent-based spatiotemporal integrated approach to simulating in-home water and related energy use behaviour: A test case of Beijing, China. Science of the Total Environment, 708, p. 135086, 2020.

[10] Correia de Araujo, W., Oliveira Esquerre, K.P. \& Sahin, O., Building a system dynamics model to support water management: A case study of the semiarid region in the Brazilian Northeast. Water, 11(12), p. 2513, 2019.

[11] Chhipi-Shrestha, G., Hewage, K. \& Sadiq, R., Economic and energy efficiency of netzero water communities: System dynamics analysis. Journal of Sustainable Water in the Built Environment, 4(3), p. 04018006, 2018.

[12] Tidwell, V.C., Passell, H.D. \& Conrad, S.H. \& Thomas, R.P., System dynamics modeling for community-based water planning: Application to the Middle Rio Grande. Aquatic Sciences, 66(4), pp. 357-372, 2004.

[13] Jeong, S. \& Park, J. Evaluating urban water management using a water metabolism framework: A comparative analysis of three regions in Korea. Resources, Conservation and Recycling, 155, p. 104597, 2020.

[14] Pluchinotta, I. et al., A participatory system dynamics model to investigate sustainable urban water management in Ebbsfleet Garden City. Sustainable Cities and Society, 67, p. 102709, 2021.

[15] CIRIA, Blue-Green Infrastructure: Perspectives on Water Quality Benefits, London: CIRIA, C780b, 2019.

[16] Krivtsov, V., Corliss, J., Bellinger, E. \& Sigee, D., Indirect regulation rule for consecutive stages of ecological succession. Ecological Modelling, 133(1-2), pp. 7381,2000 . 
[17] Krivtsov, V., Investigations of indirect relationships in ecology and environmental sciences: A review and the implications for comparative theoretical ecosystem analysis. Ecological Modelling, 174(1-2), pp. 37-54, 2004.

[18] Krivtsov, V., Study of cause-and-effect relationships in the formation of biocenoses: Their use for the control of eutrophication. Russ J Ecol. 32(4), pp. 230-234, 2001.

[19] Krivtsov, V., Indirect effects in ecology. Encyclopedia of Ecology, ed. S.E. Jorgensen \& B. D. Fath, Newnes, pp. 1948-1958, 2008.

[20] Ahilan, S. et al., Modelling the long-term suspended sedimentological effects on stormwater pond performance in an urban catchment. Journal of Hydrology, 571, pp. 805-818, 2019.

[21] Woods-Ballard, B., Kellagher, R., Martin, R., Jefferies, C., Bray, R. \& Shaffer, P., The SuDS Manual, London: CIRIA C697, 2007.

[22] Jørgensen, S.E., Fundamentals of Ecological Modelling, 2nd ed., Elsevier: Amsterdam, 1994.

[23] Krivtsov, V., Bellinger, E., Sigee, D. \& Corliss, J., Interrelations between Si and P biogeochemical cycles: A new approach to the solution of the eutrophication problem. Hydrological Processes, 14(2), pp. 283-295, 2000.

[24] Krivtsov, V., Goldspink, C., Sigee, D.C. \& Bellinger, E.G., Expansion of the model 'Rostherne' for fish and zooplankton: Role of top-down effects in modifying the prevailing pattern of ecosystem functioning. Ecological Modelling, 138(1-3), pp. 153$171,2001$.

[25] Krivtsov, V., Sigee, D., Corliss, J. \& Bellinger, E., Examination of the phytoplankton of Rostherne Mere using a simulation mathematical model. Hydrobiologia, 414, pp. 71-76, 1999.

[26] Schank, R.C., Berman, T.R. \& Macpherson, K.A., Learning by doing. InstructionalDesign Theories and Models: A New Paradigm of Instructional Theory, ed. C.M. Reigeluth, vol. 2, Lawrence Earlbaum Associates, pp. 161-181, 1999.

[27] Bandura, A., Social Learning Theory, General Learning Press: New York, 1971.

[28] CIRIA, Blue-Green Infrastructure: Perspectives on Planning, Evaluation and Collaboration, London: CIRIA, C780a, 2019.

[29] Krivtsov, V. et al., Flood resilience, amenity and biodiversity benefits of an historic urban pond. Philosophical Transactions of the Royal Society A, 378(2168), p. 20190389, 2020. 